\title{
PLA and PP Composite Nonwoven with Antimicrobial Activity for Filtration Applications
}

\author{
Marta Latwińska, Jadwiga Sójka-Ledakowicz, Jerzy Chruściel, and Maciej Piórkowski
}

Textile Research Institute, ul. Brzezińska 5/15, 92-103 Łódź, Poland

Correspondence should be addressed to Marta Łatwińska; mlatwinska@iw.lodz.pl

Received 24 June 2016; Revised 8 September 2016; Accepted 29 September 2016

Academic Editor: Victor Sebastian

Copyright (C) 2016 Marta Łatwińska et al. This is an open access article distributed under the Creative Commons Attribution License, which permits unrestricted use, distribution, and reproduction in any medium, provided the original work is properly cited.

The PLA (50\% wt.)/PP (50\% wt.), PLA (47.5\% wt.)/PP (47.5\% wt.)/paraffin (5\% wt.), and PLA (47.25\% wt.)/PP (47.25\% wt.)/paraffin (5\% wt.)/CuO $\mathrm{SiO}_{2}(0.5 \%$ wt.) composite nonwovens were obtained in one-step process by using the melt-blown technique. Thermal properties (by the DSC method), physicomechanical parameters, specific surface area, the structure (by the SEM method), the elemental analysis (by the EDS method), and susceptibility to hydrolytic degradation (in alkaline and neutral media) were studied for all the obtained nonwovens. The antimicrobial properties of the composite nonwovens were determined by using dynamic contact conditions method, with three kinds of microorganisms applied. The DSC analysis of nonwovens revealed that the mixing of PLA and PP caused the decrease in homogeneity of both polymers, as well as a considerable increase in the PLA crystallization enthalpy. The paraffin and $\mathrm{CuO} \cdot \mathrm{SiO}_{2}$ addition to PLA/PP nonwoven generally improved the filtration properties and downgraded tensile strength. Among all the tested composite nonwovens, the PLA/PP/paraffin/CuO $\cdot \mathrm{SiO}_{2}$ was the most and the PLA/PP/paraffin was the least susceptible to hydrolytic degradation in both media used in the study. The PLA/PP/paraffin/CuO·SiO 2 composite nonwoven revealed strong antibacterial activity and slight activity against the yeast.

\section{Introduction}

Among biodegradable polymers, poly(lactic acid) (PLA) is considered to be commercial and relatively cheap synthetic polymer characterized by good processing properties [1]. In the 1990s, the PLA of high molecular mass was obtained and introduced on an industrial scale, which is why since then the scientific publishing has observed a notably higher interest in the polymer; only in 2008 were over 1100 papers concerning PLA published [1]. PLA has been extensively used in the industrial production to manufacture packaging, cups for beverages, bottles, and nonwovens used for various purposes [2].

Good mechanical properties as well as excellent processing properties and a low cost of production make the traditional, nonbiodegradable synthetic polymers based on polyolefins, for example, polypropylene (PP) and polyethylene (PE), highly popular in everyday life. These polymers are used in agriculture, medicine, and industry, including the production of building materials and packaging [3].
Nevertheless, the polymers based on polyolefins are nonbiodegradable and raise serious concerns connected with their disposal and subsequent influence on the environment.

So far, scientific papers have mentioned composites which consist of biodegradable and nonbiodegradable polymers, which, thanks to the use of proper ingredients, may help obtain anticipated properties (e.g., mechanical ones), required biodegradation rate and an economically viable price point. As PLA and PP are characterized by similar melting temperatures, the composites which consist of the two polymers are produced in the course of thermal processing. The composites obtained by the melt-blending technique which comprise up to $50 \%$ of PLA were described by Choudhary et al. [4]. The analysis of the mechanical properties of the composites indicated a significant improvement in the properties of PLA influenced by the presence of PP. Reddy et al. have worked on the composites which consisted of PP, PLA (up to 10\%), and oat hull [5]. The composites were obtained by the injection moulding method. The mechanical properties of the PLA/PP set were only slightly better than 
the properties of PP alone, while, after the addition of the oat hull and a compatibilizer, some mechanical properties of the composite have improved by $40 \%$ in relation to PP. Composite PLA/PP fibres, where the proportion of PLA ranges from 0 to $100 \%$, were analysed by Reddy et al. [6]. It turned out that composite fibres had worse mechanical properties compared to the fibres made from pure polymers. PLA in the composites was characterized by higher resistance to biodegradation and hydrolysis; moreover, the obtained fibres were more susceptible to dying than fibres made from pure PLA and PP.

The ions of some metals, such as silver $(\mathrm{Ag})$, zinc $(\mathrm{Zn})$, titanium $(\mathrm{Ti})$, and copper $(\mathrm{Cu})$, as well as their oxides, are characterized by very strong antimicrobial properties [7-10], which is why they may be used for the functionalization of polymer materials. The easiest ways to obtain antimicrobial properties are by the direct implementation of the biocide agent into bulk polymers during processing or by using the surface modification $[11,12]$. The examples of the practical use of polymer material whose antimicrobial properties were obtained through ions or oxides of metals may be found, for example, in the works by Park (food packaging) [13], Borkow et al. (filters) [14], and Weinberg et al. (materials for hygienic purposes) [15].

The purpose of the current study was to obtain PLA/PP composite nonwovens using the melt-blown technique and to analyse their properties. Apart from requisite mechanical properties and increased biodegradation rate (in comparison to the PP nonwovens), it was planned to induce antimicrobial properties with the use of the $\mathrm{CuO} \cdot \mathrm{SiO}_{2}$ addition.

\section{Materials and Methods}

Poly(lactic acid) (PLA) was purchased in NatureWorks LLC, type Ingeo ${ }^{\mathrm{TM}}$ Biopolymer 3251D, melt flow rate (MFR) 30$40 \mathrm{~g} / 10 \mathrm{~min}\left(190^{\circ} \mathrm{C} / 2.16 \mathrm{~kg}\right)$, melting point $(\mathrm{mp}) 160-170^{\circ} \mathrm{C}$, and density $1.24 \mathrm{~g} / \mathrm{cm}^{3}$. Polypropylene (PP) was purchased in Borealis, type HL $612 \mathrm{FB}$, MFR $1200 \mathrm{~g} / 10 \mathrm{~min}\left(230^{\circ} \mathrm{C} / 2.16 \mathrm{~kg}\right)$, $\mathrm{mp} 158^{\circ} \mathrm{C}$, and density $0.9-1.0 \mathrm{~g} / \mathrm{cm}^{3}$.

The following chemical reagents were applied: liquid paraffin (purchased in PPH Aflopa), copper (II) oxide/silicon dioxide composite $\left(\mathrm{CuO} \cdot \mathrm{SiO}_{2}\right.$, composite granulation $460 \mathrm{~nm}$, provided by Institute of Chemical Technology and Engineering, Poznań University of Technology, Poland [16]), tetraborate buffer $\left(\mathrm{pH}=10, \mathrm{Na}_{2} \mathrm{~B}_{4} \mathrm{O}_{7} 0.130 \mathrm{~mol} / \mathrm{dm}^{3}+\mathrm{NaOH}\right.$ $\left.0.060 \mathrm{~mol} / \mathrm{dm}^{3}\right)$, and phosphate buffer $\left(\mathrm{pH}=7, \mathrm{KH}_{2} \mathrm{PO}_{4}\right.$ $0.071 \mathrm{~mol} / \mathrm{dm}^{3}+\mathrm{K}_{2} \mathrm{HPO}_{4} 0.117 \mathrm{~mol} / \mathrm{dm}^{3}$ ).

The composite nonwovens were obtained using the meltblown technique, which is an integrated nonwoven technology which consists in linking the fibre-forming process with web-forming process. The strings of molten polymer come out of the extruder head through the multihole nozzle, where they are blown up by the stream of hot compressed air and set as fine fibres on a collecting drum (Figure 1). Laboratory one-screw extruder (Axon product) with head (with 30 holes of $0.35 \mathrm{~mm}$ diameter each), compressed air heater, and collecting drum were used.

Three kinds of composite nonwovens were obtained: PLA (50\% wt.)/PP (50\% wt.), PLA (47.5\% wt.)/PP (47.5\% wt.)/ paraffin (5\% wt.), and PLA (47.25\% wt.)/PP (47.25\% wt.)/ paraffin ( $5 \%$ wt.) $/ \mathrm{CuO} \cdot \mathrm{SiO}_{2}$ (0.5\% wt.). Direct (one-step) method was applied, which means that the assumed masses of components were weighed, mixed, and then placed in the extruder feeding hopper. In all cases, the temperature in the zones of the extruder ranged from 220 to $270^{\circ} \mathrm{C}$, while for the hot compressed air it was set at $280^{\circ} \mathrm{C}$, with the compressed air consumption of $7 \mathrm{~m}^{3} / \mathrm{h}$ and polymer consumption of $4 \mathrm{~g} / \mathrm{min}$. PLA was dried before processing for $3 \mathrm{~h}$ at $100^{\circ} \mathrm{C}$. All the obtained nonwovens were subject to the comprehensive analysis of their properties.

Thermal properties were studied by using differential scanning calorimetry (DSC) method, on DSC 6200 Exstar SII NanoTechnology apparatus (Seiko product). Samples (ca. $5 \mathrm{mg}$ ) were heated in the nitrogen atmosphere $(50 \mathrm{~mL} / \mathrm{min})$ to $200^{\circ} \mathrm{C}$ and then cooled to $25^{\circ} \mathrm{C}$, with the scanning speed of $5^{\circ} \mathrm{C} / \mathrm{min}$. Samples were evaluated in triplicate.

The following physicomechanical parameters of the composite nonwovens were analysed: mass per unit area (according to PN-EN 29073-1:1994), fibre diameter (according to PNISO 137:2000, with the exception of the number of measurements and the preparation of samples), average air permeability (according to PN-EN ISO 9237:1998), and average maximum breaking force and relative elongation at maximum force (according to PN-EN 29073-3:1994).

Specific surface area was analysed for samples of the composite nonwovens (samples mass was ca. $2 \mathrm{~g}$ ) using the 5-point Brunauer-Emmett-Teller (BET) method and nitrogen as a sorption agent, on Autosorb-1 apparatus (Quantochrome Instruments product).

The structural analysis of the composite nonwovens was performed by the scanning electron microscopy (SEM) method using VEGA 3 LMU apparatus (Tescan product), with samples magnification 1000x. The elemental analysis of the $\mathrm{PLA} / \mathrm{PP} /$ paraffin/ $\mathrm{CuO} \cdot \mathrm{SiO}_{2}$ nonwoven was performed by the energy dispersive spectroscopy (EDS) method using EDS INCA Energy X-ray microanalyzer (Oxford Instruments Analytical product) connected with VEGA 3 LMU apparatus. The EDS analysis was conducted in low vacuum conditions, with $20 \mathrm{keV}$ energy of the beam of electrons and without the use of a conductive additive.

The antimicrobial properties of the composite nonwovens were determined by using the dynamic contact conditions method, according to ASTM E2149-13a. Samples mass $1 \pm$ $0.1 \mathrm{~g}$, shaking time of $1 \mathrm{~h}$, and phosphate buffer as reagent were applied. PP nonwoven constituted the reference sample. The growth reduction of microorganisms on the tested sample versus the reference one was evaluated. Two kinds of bacteria (Gram (-) Escherichia coli and Gram (+) Staphylococcus aureus) and one type of yeast (Candida albicans) were applied. Samples of the PLA/PP/paraffin/ $\mathrm{CuO} \cdot \mathrm{SiO}_{2}$ nonwoven were evaluated in triplicate and samples of the other composite nonwovens were evaluated in duplicate.

The hydrolytic degradation of the composite nonwovens (according to PN-EN ISO 10993-13:2002) was carried out using ca. $1 \mathrm{~g}$ samples, in alkaline (tetraborate buffer) and neutral (phosphate buffer) medium, at $65^{\circ} \mathrm{C}$. Samples were evaluated, in duplicate, for change in mass after $21,42,63$, and 84 days. 


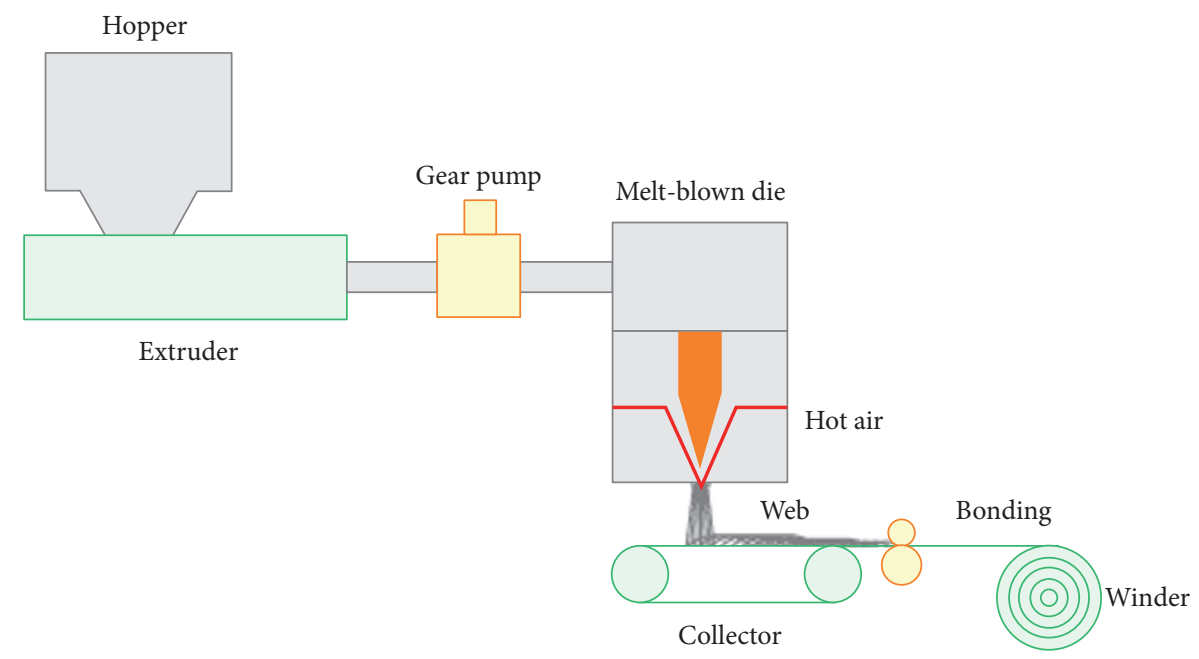

FIGURE 1: Obtaining of the nonwovens according to the melt-blown technique (http://www.kasen.co.jp/english/product/line/work.html).

\section{Results and Discussion}

3.1. Nonwovens Composition. During research works PLA (50\% wt.)/PP (50\% wt.) composite nonwoven was successfully obtained in a one-step melt-blown process. The challenge of this task was to find the appropriate temperature parameters for the process-sufficiently high to obtain fine fibres and sufficiently low to avoid the thermal decomposition of PLA.

In the next stage of the work it was planned to provide the PLA/PP composite nonwoven with antimicrobial properties by adding $\mathrm{CuO} \cdot \mathrm{SiO}_{2}$. The addition of a plasticiser was necessary to incorporate the powdery additive of $\mathrm{CuO} \cdot \mathrm{SiO}_{2}$ to melt-blown nonwoven by the direct (one-step) method. It was found out that liquid paraffin in the amount of $5 \%$ wt. was the best plasticiser for the PLA/PP composite nonwovens.

Previous research works with pure PP and pure PLA nonwovens functionalized with $\mathrm{CuO} \cdot \mathrm{SiO}_{2}$ revealed that $0.1 \%$ and $0.25 \% \mathrm{CuO} \cdot \mathrm{SiO}_{2}$ content did not provide sufficient antimicrobial activity, especially towards Candida albicans [17]. In that case the use of at least $0.5 \%$ of this additive was needed. While obtaining the $\mathrm{PLA} / \mathrm{PP} /$ paraffin $/ \mathrm{CuO} \cdot \mathrm{SiO}_{2}$ nonwovens, the irregular operation of the extruder (which resulted in significantly different mass per unit area of subsequent nonwovens) was noticed. According to our experience, it was a signal that-due to the presence of the powdery additive-the extruder head may have clogged. In this situation, the increase of the $\mathrm{CuO} \cdot \mathrm{SiO}_{2}$ ratio in the nonwoven was fraught with risk.

3.2. Thermal Properties Analysis. The DSC thermograms of pure PLA and PP nonwovens and of the three kinds of composite nonwovens (PLA/PP, PLA/PP/paraffin, and PLA/PP/ paraffin $/ \mathrm{CuO} \cdot \mathrm{SiO}_{2}$ ) were presented in Figure 2. The data obtained for these nonwovens were contained in Table 1.

Peaks numbering in Table 1 was established on the basis of the sequence in which the peaks appeared in the DSC thermograms, which means that Peaks 1,2, and 3 are consecutive peaks from the left on the bottom curve (corresponding to the heating process) and Peaks 4 and 5 are consecutive peaks from the right on the top curve (corresponding to the cooling process) (Figure 2).

Having analysed the data in Table 1 , it can be stated that the mixing of PLA and PP caused the decrease of temperatures of all peaks which appeared on pure PLA and pure PP nonwovens thermograms (Figures 2(a) and 2(b)). This phenomenon can be explained by the decrease in homogeneity of PLA and PP as a consequence of polymers mixing.

In the case of the composite nonwovens, the temperatures of peaks either decreased after the addition of the subsequent component or decreased after the addition of paraffin and then increased after the addition of $\mathrm{CuO} \cdot \mathrm{SiO}_{2}$. The first tendency was observed for the endothermic processes peaks, that is, Peaks 1 (PLA glass transition) and Peaks 3 (simultaneous PLA and PP melting) (Figures 2(c), 2(d), and 2(e)). The second tendency concerned the exothermic processes peaks, that is, Peaks 2 (PLA recrystallization), Peaks 4 (PP crystallization), and Peaks 5 (PLA crystallization). It can be assumed that the paraffin and $\mathrm{CuO} \cdot \mathrm{SiO}_{2}$ addition decreased the homogeneity of the PLA/PP composite nonwoven, which resulted in the decrease of temperature during the endothermic processes. The tendency observed for exothermic processes could be explained by the decrease in the number of crystallization nuclei after the paraffin addition and the increase in the number of crystallization nuclei after the subsequent $\mathrm{CuO} \cdot \mathrm{SiO}_{2}$ addition. The high number of the crystallization nuclei (as a consequence of the $\mathrm{CuO} \cdot \mathrm{SiO}_{2}$ presence) particularly influenced the PP and PLA crystallization temperatures (Peaks 4 and 5), which resulted in higher temperatures in the case of the $\mathrm{PLA} / \mathrm{PP} /$ paraffin $/ \mathrm{CuO} \cdot \mathrm{SiO}_{2}$ nonwoven as compared to other composite nonwovens or even to pure PLA and pure PP nonwovens.

While analysing the PLA glass transition enthalpy (Peaks 1 ), the following changes of the absorbed energy were observed (Table 1): a decrease after the mixing of PLA and $\mathrm{PP}$ and a slight growth after paraffin and $\mathrm{CuO} \cdot \mathrm{SiO}_{2}$ addition 


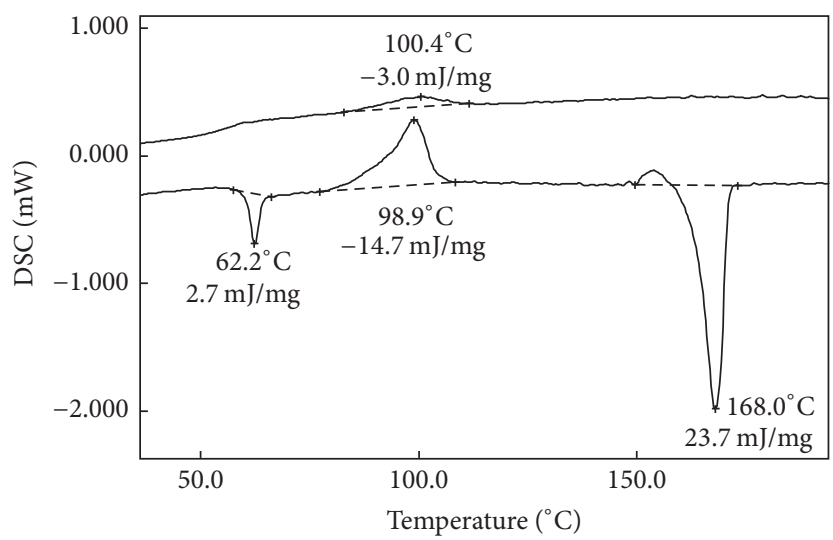

(a)

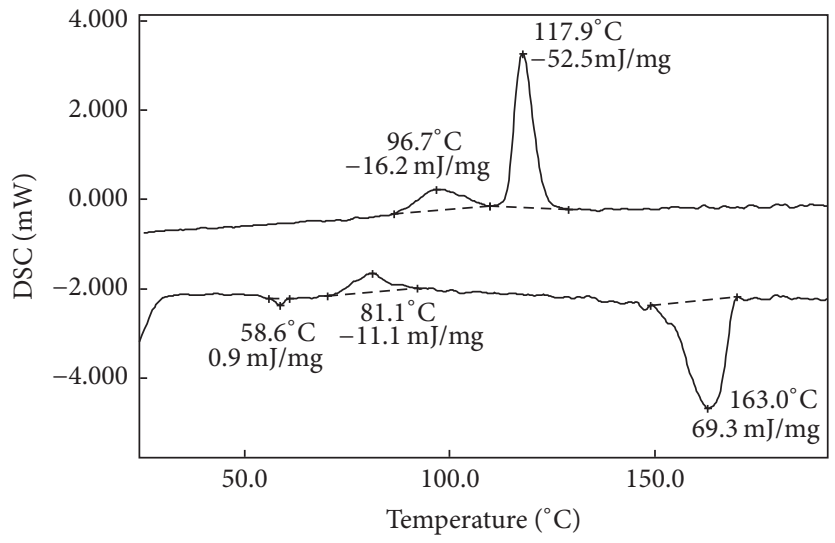

(c)

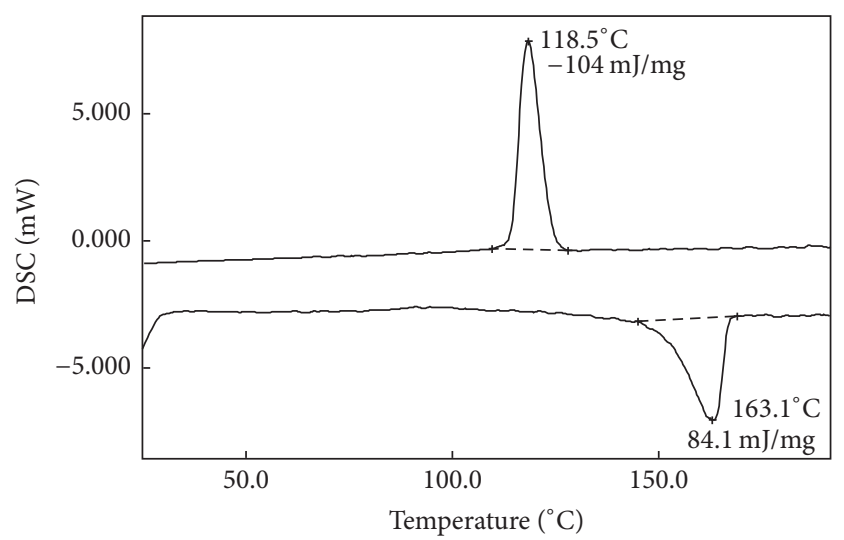

(b)

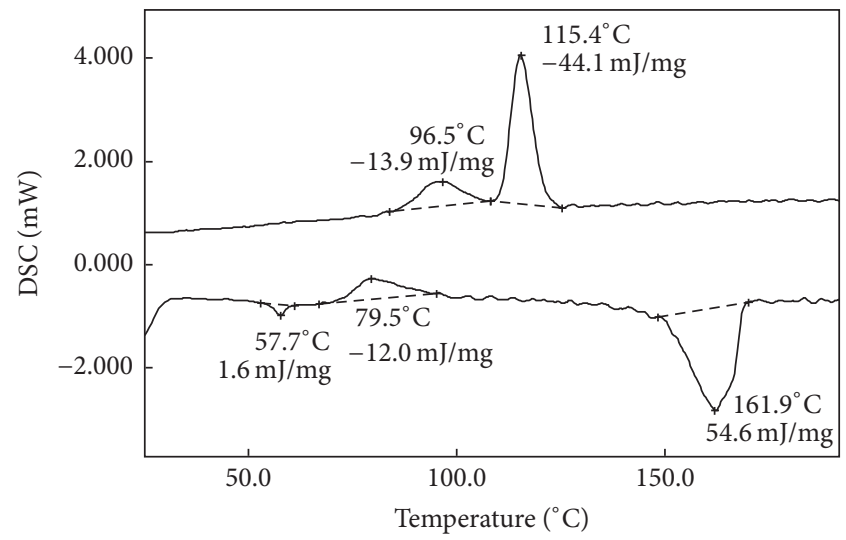

(d)

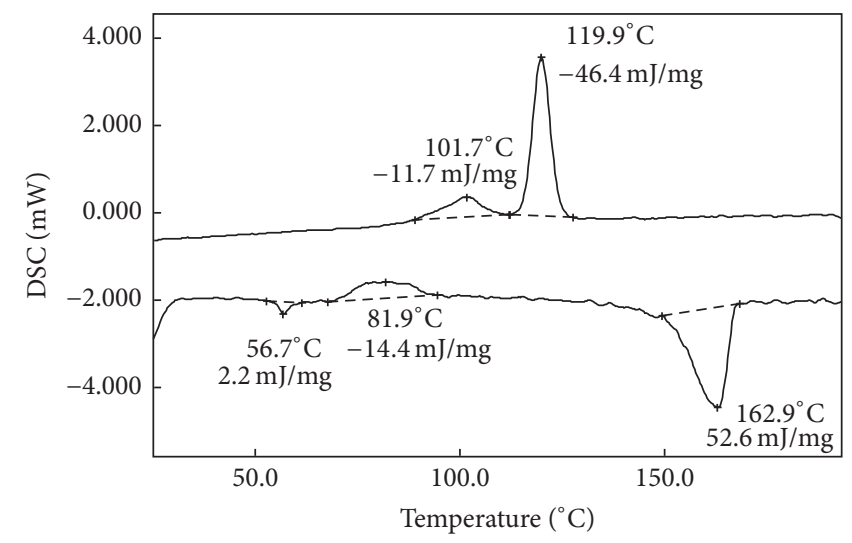

(e)

FIgURE 2: DSC thermograms of the nonwovens: (a) PLA, (b) PP, (c) PLA/PP, (d) PLA/PP/paraffin, and (e) PLA/PP/paraffin/CuO·SiO 2 .

to the PLA/PP composite nonwoven. The amount of PP in the composite nonwoven sample determined the enthalpy in the case of PLA and PP simultaneous melting process (Peaks 3). It resulted from the fact that the PP melting enthalpy is over three times greater than the PLA one and even slight differences in PLA/PP ratio in the samples caused significant changes in the obtained enthalpy of simultaneous melting process (Table 1). In the case of exothermic processes (Peaks 2,4 , and 5), no clear tendency regarding enthalpy emerged, except for significant increase in PLA crystallization enthalpy after the mixing of PLA and PP (Peaks 5). It may indicate that PLA is less amorphous in the composite nonwovens compared to a pure PLA one. The apparent decrease in PP crystallization enthalpy visible when pure PP nonwoven is compared with the composite nonwovens (Peaks 4 ) is caused by a smaller PP content in the latter.

3.3. Physicomechanical Parameters. The physicomechanical parameters of composite nonwovens were presented in Table 2. As the values of mass per unit areas of all analysed 
TABLE 1: Temperatures $(T)$ and enthalpies $(\Delta H)$ ascribed to peaks on the DSC thermograms of nonwovens.

\begin{tabular}{|c|c|c|c|c|c|}
\hline $\begin{array}{l}\text { Number } \\
\text { of peak }\end{array}$ & PLA nonwoven & PP nonwoven & $\begin{array}{c}\mathrm{PLA} / \mathrm{PP} \\
\text { nonwoven }\end{array}$ & $\begin{array}{c}\mathrm{PLA} / \mathrm{PP} / \text { paraffin } \\
\text { nonwoven }\end{array}$ & $\begin{array}{c}\mathrm{PLA} / \mathrm{PP} / \text { paraffin } / \mathrm{CuO} \cdot \mathrm{SiO}_{2} \\
\text { nonwoven }\end{array}$ \\
\hline 1 & $\begin{array}{c}62.2 \pm 0.1^{\circ} \mathrm{C}(T) \\
2.7 \pm 0.1 \mathrm{~J} / \mathrm{g}(\Delta H)\end{array}$ & - & $\begin{array}{c}58.5 \pm 0.1^{\circ} \mathrm{C}(T) \\
1.3 \pm 0.2 \mathrm{~J} / \mathrm{g}(\Delta H)\end{array}$ & $\begin{array}{c}58.1 \pm 0,2^{\circ} \mathrm{C}(T) \\
1.5 \pm 0,1 \mathrm{~J} / \mathrm{g}(\Delta H)\end{array}$ & $\begin{array}{c}56.5 \pm 0.4^{\circ} \mathrm{C}(T) \\
2.0 \pm 0.1 \mathrm{~J} / \mathrm{g}(\Delta H)\end{array}$ \\
\hline 2 & $\begin{array}{c}98.8 \pm 0.3^{\circ} \mathrm{C}(T) \\
-14.8 \pm 0.1 \mathrm{~J} / \mathrm{g}(\Delta H)\end{array}$ & - & $\begin{array}{c}80.8 \pm 0.5^{\circ} \mathrm{C}(T) \\
-10.6 \pm 0.3 \mathrm{~J} / \mathrm{g}(\Delta H)\end{array}$ & $\begin{array}{c}80.0 \pm 0.4^{\circ} \mathrm{C}(T) \\
-12.8 \pm 0.6 \mathrm{~J} / \mathrm{g}(\Delta H)\end{array}$ & $\begin{array}{c}81.8 \pm 0.2^{\circ} \mathrm{C}(T) \\
-14.5 \pm 0.5 \mathrm{~J} / \mathrm{g}(\Delta H)\end{array}$ \\
\hline 3 & $\begin{array}{c}168.0 \pm 0.1^{\circ} \mathrm{C}(T) \\
24.4 \pm 0.4 \mathrm{~J} / \mathrm{g}(\Delta H)\end{array}$ & $\begin{array}{c}162.6 \pm 0.6^{\circ} \mathrm{C}(T) \\
84.0 \pm 0.1 \mathrm{~J} / \mathrm{g}(\Delta H)\end{array}$ & $\begin{array}{c}162.9 \pm 0.1^{\circ} \mathrm{C}(T) \\
64.7 \pm 2.3 \mathrm{~J} / \mathrm{g}(\Delta H)\end{array}$ & $\begin{array}{l}162.4 \pm 0.4^{\circ} \mathrm{C}(T) \\
53.1 \pm 1.5 \mathrm{~J} / \mathrm{g}(\Delta H)\end{array}$ & $\begin{array}{c}162.4 \pm 0.2^{\circ} \mathrm{C}(T) \\
54.5 \pm 1.0 \mathrm{~J} / \mathrm{g}(\Delta H)\end{array}$ \\
\hline 4 & - & $\begin{array}{c}118.3 \pm 0.2^{\circ} \mathrm{C}(T) \\
-103.7 \pm 0.9 \mathrm{~J} / \mathrm{g}(\Delta H)\end{array}$ & $\begin{array}{c}117.9 \pm 0.1^{\circ} \mathrm{C}(T) \\
-49.3 \pm 1.6 \mathrm{~J} / \mathrm{g}(\Delta H)\end{array}$ & $\begin{array}{c}115.2 \pm 0.1^{\circ} \mathrm{C}(T) \\
-42.4 \pm 0.9 \mathrm{~J} / \mathrm{g}(\Delta H)\end{array}$ & $\begin{array}{c}119.9 \pm 0.1^{\circ} \mathrm{C}(T) \\
-49.2 \pm 2.0 \mathrm{~J} / \mathrm{g}(\Delta H)\end{array}$ \\
\hline 5 & $\begin{array}{c}100.2 \pm 0.6^{\circ} \mathrm{C}(T) \\
-3.8 \pm 0.4 \mathrm{~J} / \mathrm{g}(\Delta H)\end{array}$ & - & $\begin{array}{c}96.9 \pm 0.2^{\circ} \mathrm{C}(T) \\
-13.8 \pm 1.2 \mathrm{~J} / \mathrm{g}(\Delta H)\end{array}$ & $\begin{array}{c}96.3 \pm 0.1^{\circ} \mathrm{C}(T) \\
-13.4 \pm 0.2 \mathrm{~J} / \mathrm{g}(\Delta H)\end{array}$ & $\begin{array}{c}101.5 \pm 0.2^{\circ} \mathrm{C}(T) \\
-11.8 \pm 0.2 \mathrm{~J} / \mathrm{g}(\Delta H)\end{array}$ \\
\hline
\end{tabular}

TABLE 2: Mass per unit area, fibre diameter, average air permeability, average maximum breaking force, and relative elongation at maximum force of the composite nonwovens.

\begin{tabular}{|c|c|c|c|}
\hline Analysed parameter & $\begin{array}{c}\text { PLA/PP } \\
\text { nonwoven }\end{array}$ & $\begin{array}{c}\mathrm{PLA} / \mathrm{PP} / \text { paraffin } \\
\text { nonwoven }\end{array}$ & $\begin{array}{c}\mathrm{PLA} / \mathrm{PP} / \text { paraffin } / \mathrm{CuO} \cdot \mathrm{SiO}_{2} \\
\text { nonwoven }\end{array}$ \\
\hline Mass per unit area $\left(\mathrm{g} / \mathrm{m}^{2}\right)$ & $159 \pm 3$ & $143 \pm 2$ & $149 \pm 10$ \\
\hline \multicolumn{4}{|l|}{ Fibre diameter $(\mu \mathrm{m})$} \\
\hline Average & 8.91 & 7.75 & 4.23 \\
\hline Minimal & 2.17 & 1.99 & 0.91 \\
\hline Maximal & 22.89 & 20.72 & 10.09 \\
\hline \multicolumn{4}{|l|}{$\begin{array}{l}\text { Average air permeability } \\
(\mathrm{mm} / \mathrm{s})\end{array}$} \\
\hline $100 \mathrm{~Pa}$ & $468 \pm 17$ & $510 \pm 20$ & $426 \pm 25$ \\
\hline $200 \mathrm{~Pa}$ & $920 \pm 30$ & $990 \pm 30$ & $840 \pm 50$ \\
\hline \multicolumn{4}{|l|}{$\begin{array}{l}\text { Average maximum breaking } \\
\text { force }(\mathrm{N})\end{array}$} \\
\hline Machine direction & $42.6 \pm 4.2$ & $33.3 \pm 4.0$ & $10.8 \pm 1.9$ \\
\hline Cross direction & $34.1 \pm 1.1$ & $26.4 \pm 3.4$ & $8.2 \pm 3.1$ \\
\hline \multicolumn{4}{|l|}{$\begin{array}{l}\text { Relative elongation at } \\
\text { maximum force }(\%)\end{array}$} \\
\hline Machine direction & $18.0 \pm 1.5$ & $28.0 \pm 3.5$ & $3.5 \pm 0.5$ \\
\hline Cross direction & $19.5 \pm 4.5$ & $25.0 \pm 8.5$ & $4.0 \pm 1.5$ \\
\hline
\end{tabular}

composite nonwovens were similar, it was possible to compare these nonwovens with respect to other physicomechanical parameters (Table 2).

The $\mathrm{PLA} / \mathrm{PP} /$ paraffin/ $\mathrm{CuO} \cdot \mathrm{SiO}_{2}$ composite nonwoven showed the smallest average fibre diameter (Table 2). For the other composite nonwovens, this parameter was approximately two times greater, and the PLA/PP/paraffin nonwoven average fibre diameter was a little smaller. The average air permeability, which is connected with the fibre diameter, was the smallest for the $\mathrm{PLA} / \mathrm{PP} / \mathrm{paraffin} / \mathrm{CuO} \cdot \mathrm{SiO}_{2}$ composite nonwoven as expected, but the other composite nonwovens showed similar value of this parameter. It can be stated that frequently observed precise correlation between the fibre diameter and the average air permeability did not occur. Analysed parameters showed good filtration properties of the $\mathrm{PLA} / \mathrm{PP} /$ paraffin/ $\mathrm{CuO} \cdot \mathrm{SiO}_{2}$ composite nonwoven.

Data concerning strength parameters indicated the lowest resistance to break and the lowest elasticity of the PLA/PP/ paraffin/ $\mathrm{CuO} \cdot \mathrm{SiO}_{2}$ composite nonwoven (Table 2). The PLA/ $\mathrm{PP} /$ paraffin composite nonwoven was about three times more resistant to break and about seven times more elastic, while the PLA/PP nonwoven was about four times more resistant to break and about five times more elastic. All the above data showed poor strength properties of the PLA/PP/paraffin/ $\mathrm{CuO} \cdot \mathrm{SiO}_{2}$ nonwoven, which probably resulted from the addition of the powdery $\mathrm{CuO} \cdot \mathrm{SiO}_{2}$. Moreover, the data confirmed the positive effect of the paraffin on the elasticity of the PLA/PP/paraffin composite nonwoven and the negative effect of the paraffin and $\mathrm{CuO} \cdot \mathrm{SiO}_{2}$ addition on the resistance to break of the PLA/PP composite nonwoven.

3.4. Specific Surface Area. The analyses did not confirm the anticipated correlation between the fibre diameter and the specific surface area of composite nonwovens (the finer the fibres are, the greater the surface area is). Taking into account measurement uncertainty, the specific surface area of all the 
TABLE 3: The elemental analysis performed by the EDS method for the PLA/PP/paraffin/CuO $\cdot \mathrm{SiO}_{2}$ composite nonwoven.

\begin{tabular}{lcccc}
\hline Analysed element & $\mathrm{C}$ & $\mathrm{O}$ & $\mathrm{Si}$ & $\mathrm{Cu}$ \\
\hline Average value & $76.83 \pm 0.41 \%$ & $22.97 \pm 0.41 \%$ & $0.08 \pm 0.01 \%$ & $0.12 \pm 0.01 \%$ \\
\hline
\end{tabular}

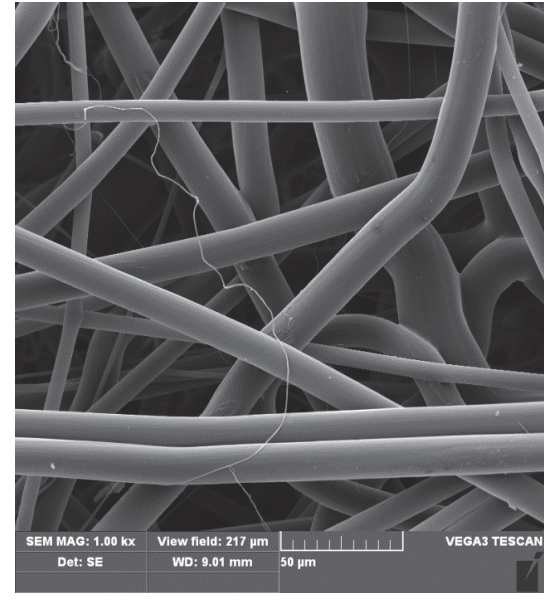

(a)

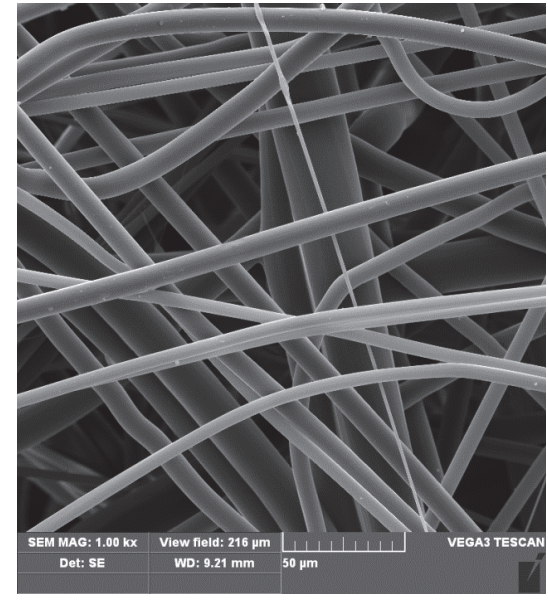

(b)

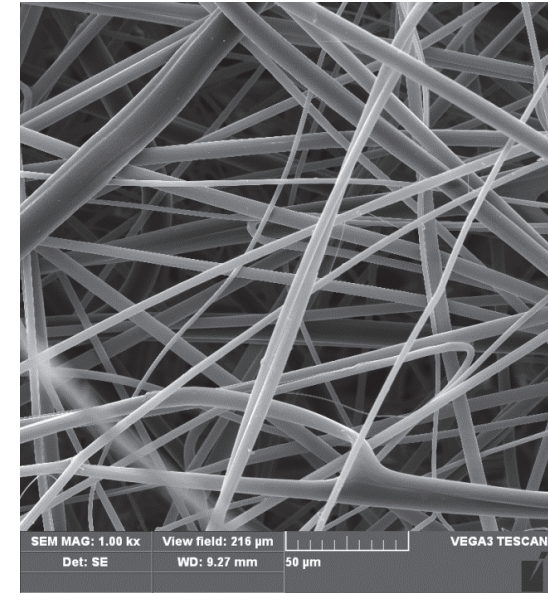

(c)

FIGURE 3: SEM images of the composite nonwovens: (a) PLA/PP, (b) PLA/PP/paraffin, and (c) PLA/PP/paraffin/CuO·SiO 2 .

tested nonwovens was the same and reached the following values: $0.37 \pm 0.03 \mathrm{~m}^{2} / \mathrm{g}$ for the PLA/PP composite nonwoven, $0.34 \pm 0.03 \mathrm{~m}^{2} / \mathrm{g}$ for the $\mathrm{PLA} / \mathrm{PP} /$ paraffin composite nonwoven, and $0.38 \pm 0.02 \mathrm{~m}^{2} / \mathrm{g}$ for the $\mathrm{PLA} / \mathrm{PP} /$ paraffin $/ \mathrm{CuO} \cdot \mathrm{SiO}_{2}$ composite nonwoven.

The values of specific surface area obtained for composite nonwovens were compared to specific surface area measured with the use of the same method for similar material-polyacrylonitrile (PAN) electrospun nanofiber nonwoven [18]. In the case of the PAN nonwoven the fibre diameter was $1.3 \mu \mathrm{m}$ and the specific surface area was $2 \mathrm{~m}^{2} / \mathrm{g}$. As the elementary fibre diameter of composite nonwovens was three to seven times greater, the specific surface area which is five times smaller correlates very well with the data obtained for the PAN nonwoven.

3.5. Structural Analysis and Elemental Analysis. Scanning electron microscope images of composite nonwovens were presented in Figure 3. Microscope scans confirmed the fibre diameter measurements: the finest fibres for the PLA/PP/paraffin $/ \mathrm{CuO} \cdot \mathrm{SiO}_{2}$ composite nonwoven, the intermediate fibres for the PLA/PP/paraffin composite nonwoven, and the thickest fibres for the PLA/PP composite nonwoven were clearly visible (Figure 3). The presence of the powdery $\mathrm{CuO} \cdot \mathrm{SiO}_{2}$ on the PLA/PP/paraffin/ $\mathrm{CuO} \cdot \mathrm{SiO}_{2}$ composite nonwoven image was anticipated; however, it was not observed (Figure 3(c)). The reason for this situation may be as little as $0.5 \% \mathrm{CuO} \cdot \mathrm{SiO}_{2}$ content in the composite nonwoven.

The data concerning the elemental analysis (X-ray microanalysis) of the $\mathrm{PLA} / \mathrm{PP} /$ paraffin/ $\mathrm{CuO} \cdot \mathrm{SiO}_{2}$ composite nonwoven were presented in Table 3 . The calculated theoretical contents of $\mathrm{Cu}$ and $\mathrm{Si}$ in the composite nonwoven were $0.23 \%$ and $0.10 \%$, respectively. It can be stated that although the content measured for $\mathrm{Si}$ is very similar to theoretical one $(0.08 \%)$, the value measured for $\mathrm{Cu}$ is 2 times smaller $(0.12 \%)$. The calculated theoretical $\mathrm{Cu} / \mathrm{Si}$ mass ratio (2.27) is also smaller than that calculated on the basis of the obtained data (1.50). Both the differences between theoretical calculations and the performed elemental analysis may stem from the partial thermal reduction of $\mathrm{CuO}$ to $\mathrm{Cu}$ which occurred during the processing. The resulting $\mathrm{Cu}$ atoms, not connected with $\mathrm{SiO}_{2}$, may easily deposit on the inner elements of the extruder.

3.6. Antimicrobial Properties. The antimicrobial activity values of the composite nonwovens were presented in Table 4. The antimicrobial activity value is the subtraction $\log \mathrm{C}-$ $\log \mathrm{A}$, where $\log \mathrm{C}$ is a $\log$ arithm of the number of colonies on the reference sample (i.e., the PP nonwoven) and $\log \mathrm{A}$ is a logarithm of the number of colonies on the analysed sample (i.e., the composite nonwoven). According to the standard EN ISO 20743:2013 and in accordance with the microbiological laboratories practise, the antimicrobial activity value below 0.5 means no activity, that between 0.5 and 2 means slight activity, that between 2 and 3 means significant activity, and that above 3 means strong activity.

It turned out that the $\mathrm{PLA} / \mathrm{PP} /$ paraffin $/ \mathrm{CuO} \cdot \mathrm{SiO}_{2} \mathrm{com}-$ posite nonwoven revealed strong antimicrobial activity towards both kinds of bacteria-Gram (-) Escherichia coli and Gram (+) Staphylococcus aureus-and practically completely reduced their growth (Table 4). In the case of yeast Candida albicans the discussed nonwoven demonstrated only slight activity. The other composite nonwovens did not reveal any antimicrobial activity, as expected. The obtained results indicated the antimicrobial properties of the PLA/PP/ 
TABLE 4: Antimicrobial activity values of the composite nonwovens.

\begin{tabular}{|c|c|c|c|}
\hline $\begin{array}{l}\text { Analysed microorganism } \\
\text { (number of strain) }\end{array}$ & $\begin{array}{c}\text { PLA/PP } \\
\text { nonwoven }\end{array}$ & $\begin{array}{c}\mathrm{PLA} / \mathrm{PP} / \text { paraffin } \\
\text { nonwoven }\end{array}$ & $\begin{array}{c}\mathrm{PLA} / \mathrm{PP} / \text { paraffin } / \mathrm{CuO} \cdot \mathrm{SiO}_{2} \\
\text { nonwoven }\end{array}$ \\
\hline $\begin{array}{l}\text { Escherichia coli } \\
\text { (ATCC 25922) }\end{array}$ & $0.0 \pm 0.0$ & $0.0 \pm 0.0$ & $3.6 \pm 0.1$ \\
\hline $\begin{array}{l}\text { Staphylococcus aureus } \\
\text { (ATCC 6538) }\end{array}$ & $0.0 \pm 0.0$ & $0.0 \pm 0.0$ & $3.9 \pm 0.1$ \\
\hline $\begin{array}{l}\text { Candida albicans } \\
\text { (ATCC 10321) }\end{array}$ & $0.0 \pm 0.0$ & $0.0 \pm 0.0$ & $1.4 \pm 0.4$ \\
\hline
\end{tabular}

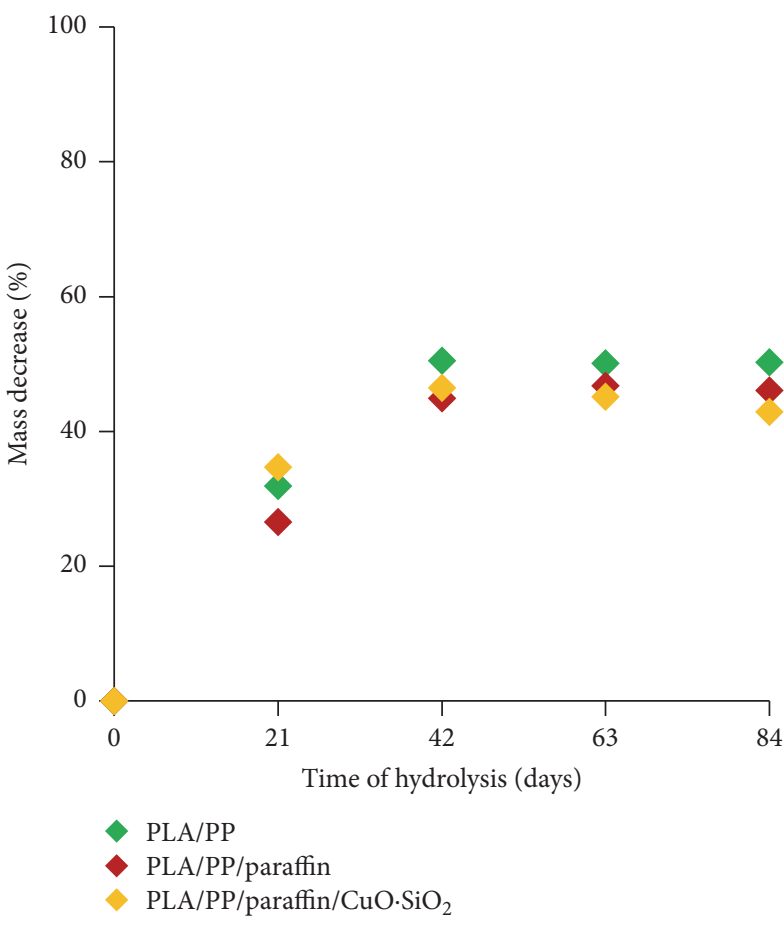

(a)

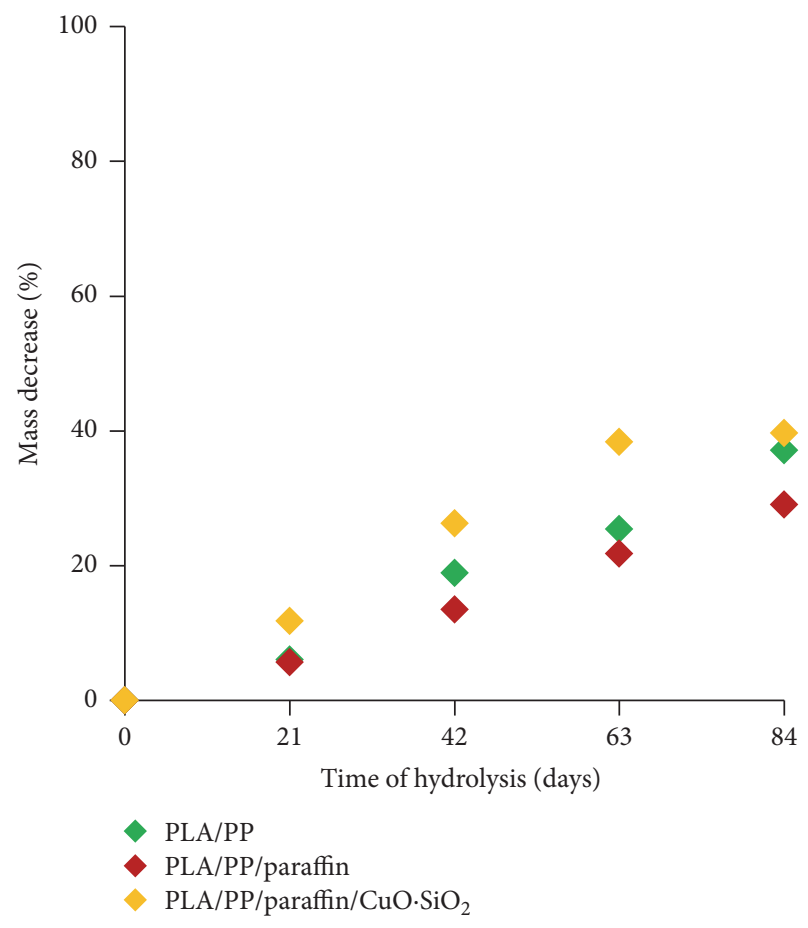

(b)

FIGURE 4: Hydrolytic degradation of the composite nonwovens: (a) in tetraborate buffer $(\mathrm{pH}=10)$ and $(\mathrm{b})$ in phosphate buffer $(\mathrm{pH}=7)$.

paraffin/ $\mathrm{CuO} \cdot \mathrm{SiO}_{2}$ composite nonwoven, although only $0.5 \%$ addition of the bioactive modifier was applied and even though the actual $\mathrm{CuO} \cdot \mathrm{SiO}_{2}$ content (measured by the X-ray microanalysis) was twice as small (about $0.25 \%$ ).

3.7. Hydrolytic Degradation. The decrease in the mass of the $\mathrm{PLA} / \mathrm{PP}, \mathrm{PLA} / \mathrm{PP} /$ paraffin, and PLA/PP/paraffin/CuO $\cdot \mathrm{SiO}_{2}$ composite nonwovens after hydrolytic degradation in different media was shown in graph (Figure 4).

Having analysed the results presented in Figure 4(a) it can be stated that the hydrolysis of all kinds of composite nonwovens in alkaline medium (more precisely, hydrolysis of PLA present in these nonwovens) was complete within 42 days. Differences in alkaline hydrolysis rates for different kinds of composite nonwovens appeared after 21 days. For this time, the greatest mass decrease for the PLA/PP/ paraffin $/ \mathrm{CuO} \cdot \mathrm{SiO}_{2}$ nonwoven (35\%), the intermediate mass decrease for the PLA/PP nonwoven (32\%), and the smallest mass decrease for the PLA/PP/paraffin nonwoven (27\%) were observed. Mass decreases of PLA alone, calculated with respect to the theoretical contents of this polymer in the composite nonwovens, were $73 \%, 64 \%$, and $56 \%$, respectively.

The hydrolysis of the composite nonwovens in the neutral medium was not finished for 84 days (Figure 4(b)). After this time, the mass decrease of the $\mathrm{PLA} / \mathrm{PP} /$ paraffin $/ \mathrm{CuO} \cdot \mathrm{SiO}_{2}$ nonwoven reached the value of $38 \%$, which corresponds to $81 \%$ mass decrease of the PLA amount theoretically contained in the nonwoven and the mass decrease of the PLA/PP nonwoven was smaller and reached $37 \%$ ( $74 \%$ of theoretical PLA contents), whereas the mass decrease of the PLA/PP/paraffin nonwoven was the smallest and amounted to $29 \%$ (62\% of theoretical PLA contents). The hydrolysis in neutral medium confirmed the tendency observed previously in the alkaline medium, that is, the fact that the $\mathrm{PLA} / \mathrm{PP} /$ paraffin $/ \mathrm{CuO} \cdot \mathrm{SiO}_{2}$ nonwoven was the most and the PLA/PP/paraffin nonwoven was the least susceptible to hydrolytic degradation among all kinds of composite nonwovens. This tendency can be explained by the changes in the hydrophilicity of the composite nonwovens-the paraffin addition to the PLA/PP 
nonwoven increased the hydrophobicity and slowed down the hydrolysis, whereas the addition of the polar $\mathrm{CuO} \cdot \mathrm{SiO}_{2}$ increased the hydrophilicity causing significant acceleration of the hydrolysis.

\section{Conclusions}

Three kinds of the composite nonwovens-PLA/PP 50/50, $\mathrm{PLA} / \mathrm{PP} /$ paraffin $47.5 / 47.5 / 5$, and $\mathrm{PLA} / \mathrm{PP} /$ paraffin $/ \mathrm{CuO} \cdot \mathrm{SiO}_{2}$ $47.25 / 47.25 / 5 / 0.5$-were obtained with the use of the meltblown technique, in a direct (one-step) process. The DSC analysis revealed that the mixing of PLA and PP caused the decrease in homogeneity of both polymers. Having compared the DSC thermograms of the composite nonwovens it was stated that the subsequent addition of paraffin and $\mathrm{CuO} \cdot \mathrm{SiO}_{2}$ to the PLA/PP nonwoven caused endothermic processes temperatures to decrease and first the decrease and then increase of the temperatures of exothermic processes. The enthalpies of all the analysed processes did not reveal any significant tendency, except for considerable increase in the PLA crystallization enthalpy after the mixing of PLA and PP, which suggested that PLA was less amorphous in the composite nonwovens compared to a pure PLA one. The analysis of the physicomechanical parameters of the composite nonwovens showed that the smallest average fibre diameter and the smallest average air permeability were demonstrated by the PLA/ $\mathrm{PP} /$ paraffin/ $\mathrm{CuO} \cdot \mathrm{SiO}_{2}$ composite nonwoven, which indicated the best filtration properties of this nonwoven. At the same time, the $\mathrm{PLA} / \mathrm{PP} /$ paraffin/ $\mathrm{CuO} \cdot \mathrm{SiO}_{2}$ composite nonwoven showed the lowest resistance to break and the lowest elasticity. The correlation between the fibre diameter and the specific surface area of the composite nonwovens was not found-the specific surface area of all the tested nonwovens was the same taking into account measurement uncertainty. Structural analysis confirmed the fibre diameter measurements - the finest fibres for the PLA/PP/paraffin/ $\mathrm{CuO} \cdot \mathrm{SiO}_{2}$ composite nonwoven and the thickest fibres for the PLA/PP composite nonwoven were clearly visible. The data concerning the elemental analysis of the PLA/PP/paraffin/ $\mathrm{CuO} \cdot \mathrm{SiO}_{2}$ composite nonwoven indicated that the real $\mathrm{Cu}$ content was twice as small as the theoretical one. It may stem from the partial thermal reduction of $\mathrm{CuO}$ to $\mathrm{Cu}$ during the processing and as a consequence of the depositing of the $\mathrm{Cu}$ atoms on the inner elements of the extruder. The analysis of the antimicrobial properties revealed strong antibacterial activity and slight activity against the yeast of the PLA/ $\mathrm{PP} /$ paraffin $/ \mathrm{CuO} \cdot \mathrm{SiO}_{2}$ composite nonwoven at as little as $0.5 \%$ active $\mathrm{CuO} \cdot \mathrm{SiO}_{2}$ addition. The other composite nonwovens did not reveal any antimicrobial activity, as expected. The hydrolysis of the composite nonwovens in alkaline and neutral media led to the conclusion that the PLA/ $\mathrm{PP} /$ paraffin $/ \mathrm{CuO} \cdot \mathrm{SiO}_{2}$ nonwoven was the most and the PLA/ $\mathrm{PP} /$ paraffin nonwoven was the least susceptible to hydrolytic degradation. This observation can be explained by the changes in hydrophilicity of the PLA/PP composite nonwoven after paraffin and then $\mathrm{CuO} \cdot \mathrm{SiO}_{2}$ addition. To summarize the conclusions, it should be highlighted that the obtained $\mathrm{PLA} / \mathrm{PP} /$ paraffin/ $\mathrm{CuO} \cdot \mathrm{SiO}_{2}$ composite nonwoven showed fine properties (with the exception of the resistance to break and the elasticity), including excellent antibacterial properties against Gram (+) and Gram (-) bacteria. For these reasons, the prepared bioactive composite nonwoven can be applied as a filtration material in multilayered systems.

\section{Competing Interests}

The authors declare that they have no competing interests.

\section{Acknowledgments}

The study was financed by Polish Ministry of Science and Higher Education within statutory research work carried out in 2015 at Textile Research Institute, Łódź, Poland. The authors thank Professor Teofil Jesionowski and his research team from the Institute of Chemical Technology and Engineering, Poznan University of Technology, for providing the copper (II) oxide/silicon dioxide composite $\left(\mathrm{CuO} \cdot \mathrm{SiO}_{2}\right)$.

\section{References}

[1] R. Auras, L.-T. Lim, S. E. M. Selke, and H. Tsuji, Poly(Lactic Acid): Synthesis, Structures, Properties, Processing, and Applications, John Wiley \& Sons, Hoboken, NJ, USA, 2010.

[2] D. Garlotta, "A literature review of poly(lactic acid)," Journal of Polymers and the Environment, vol. 9, no. 2, pp. 63-84, 2001.

[3] G. E. Luckachan and C. K. S. Pillai, "Biodegradable polymersa review on recent trends and emerging perspectives," Journal of Polymers and the Environment, vol. 19, no. 3, pp. 637-676, 2011.

[4] P. Choudhary, S. Mohanty, S. K. Nayak, and L. Unnikrishnan, "Poly(L-lactide)/polypropylene blends: evaluation of mechanical, thermal, and morphological characteristics," Journal of Applied Polymer Science, vol. 121, no. 6, pp. 3223-3237, 2011.

[5] J. P. Reddy, M. Misra, and A. Mohanty, "Injection moulded biocomposites from oat hull and polypropylene/polylactide blend: fabrication and performance evaluation," Advances in Mechanical Engineering, vol. 5, Article ID 761840, 2013.

[6] N. Reddy, D. Nama, and Y. Yang, "Polylactic acid/polypropylene polyblend fibers for better resistance to degradation," Polymer Degradation and Stability, vol. 93, no. 1, pp. 233-241, 2008.

[7] X. Xu, Q. Yang, Y. Wang, H. Yu, X. Chen, and X. Jing, "Biodegradable electrospun poly(L-lactide) fibers containing antibacterial silver nanoparticles," European Polymer Journal, vol. 42, no. 9, pp. 2081-2087, 2006.

[8] A. A. Subash, K. V. Chandramouli, T. Ramachandran, R. Rajendran, and M. Muthusamy, "Preparation, characterization, and functional analysis of zinc oxide nanoparticle-coated cotton fabric for antibacterial efficacy," Journal of the Textile Institute, vol. 103, no. 3, pp. 298-303, 2012.

[9] O. L. Galkina, A. Sycheva, A. Blagodatskiy et al., "The sol-gel synthesis of cotton/ $/ \mathrm{TiO}_{2}$ composites and their antibacterial properties," Surface and Coatings Technology, vol. 253, pp. 171-179, 2014.

[10] A. Berendjchi, R. Khajavi, and M. E. Yazdanshenas, "Fabrication of superhydrophobic and antibacterial surface on cotton fabric by doped silica-based sols with nanoparticles of copper," Nanoscale Research Letters, vol. 6, article 594, 2011.

[11] H. Palza, K. Delgado, and I. Pinochet, "Improving the metal ion release from nanoparticles embedded in a polypropylene matrix 
for antimicrobial applications," Journal of Applied Polymer Science, vol. 132, no. 1, Article ID 41232, 2014.

[12] C. Rode, M. Zieger, R. Wyrwa et al., "Antibacterial Zinc Oxide nanoparticle coating of polyester fabrics," Journal of Textile Science and Technology, vol. 1, no. 2, pp. 65-74, 2015.

[13] E. S. Park, "Antimicrobial polymeric materials for packaging applications: a review," in The Battle Against Microbial Pathogens: Basic Science, Technological Advances and Educational Programs, A. Méndez-Vilas, Ed., vol. 1, Formatex Research Center, 2015.

[14] G. Borkow, R. W. Sidwell, D. F. Smee et al., "Neutralizing viruses in suspensions by copper oxide-based filters," Antimicrobial Agents and Chemotherapy, vol. 51, no. 7, pp. 2605-2607, 2007.

[15] I. Weinberg, A. Lazary, A. Jefidoff, J. J. Vatine, G. Borkow, and N. Ohana, "Safety of using diapers containing copper oxide in chronic care elderly patients," The Open Biology Journal, vol. 6, pp. 1-7, 2013.

[16] A. Modrzejewska-Sikorska, F. Ciesielczyk, and T. Jesionowski, "Synthesis and characterisation of precipitated $\mathrm{CuO} \cdot \mathrm{SiO}_{2}$ oxide composites," Pigment and Resin Technology, vol. 41, no. 2, pp. 71-80, 2012.

[17] J. Sójka-Ledakowicz, J. J. Chruściel, M. H. Kudzin, M. Łatwińska, and M. Kiwała, "Antimicrobial functionalization of textile materials with copper silicate," Fibres and Textiles in Eastern Europe, vol. 5, no. 119, pp. 151-156, 2016.

[18] D. Hussain, F. Loyal, A. Greiner, and J. H. Wendorff, "Structure property correlations for electrospun nanofiber nonwovens," Polymer, vol. 51, no. 17, pp. 3989-3997, 2010. 

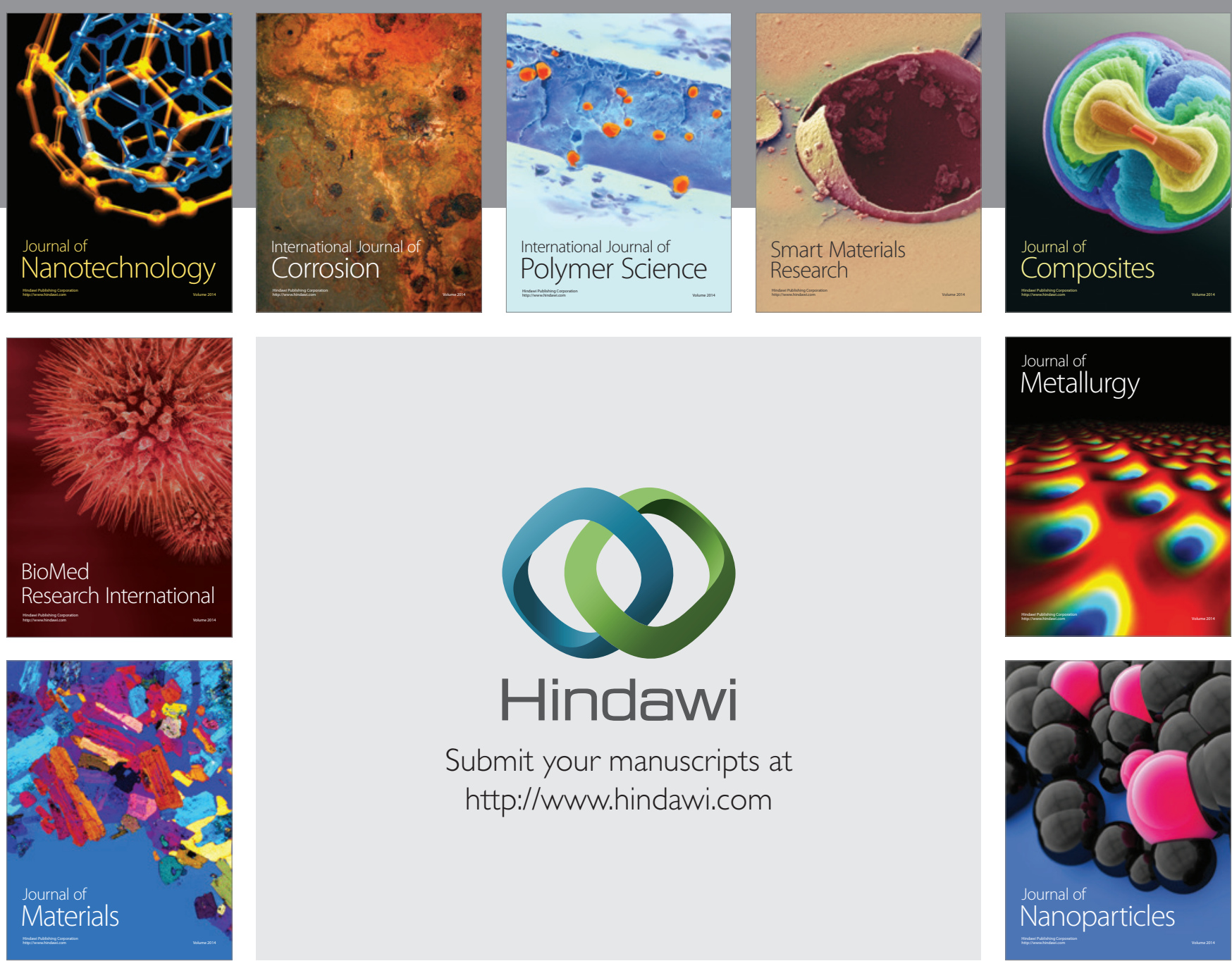

\section{Hindawi}

Submit your manuscripts at

http://www.hindawi.com

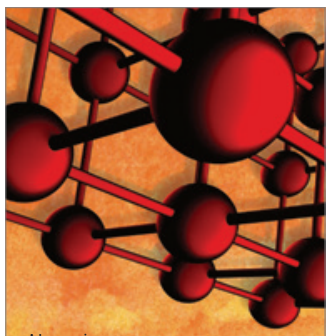

Materials Science and Engineering
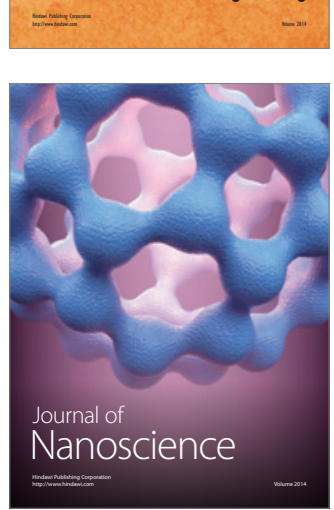
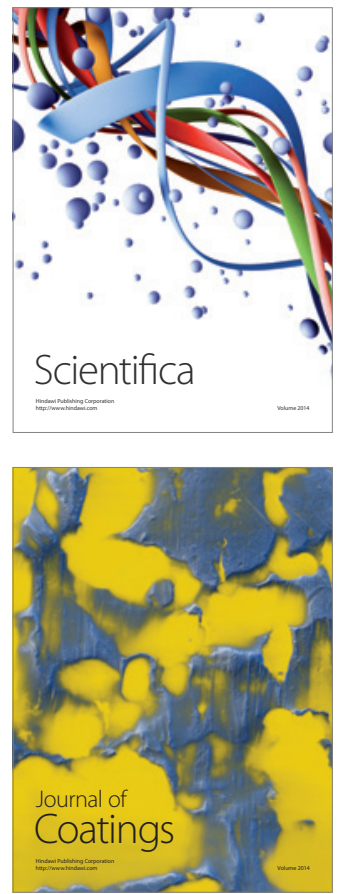
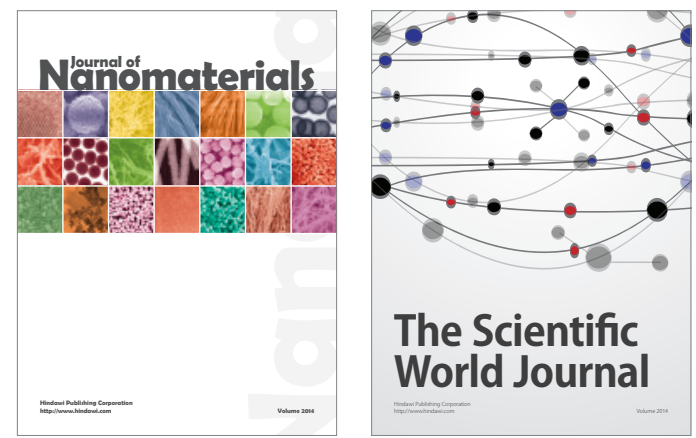

The Scientific World Journal
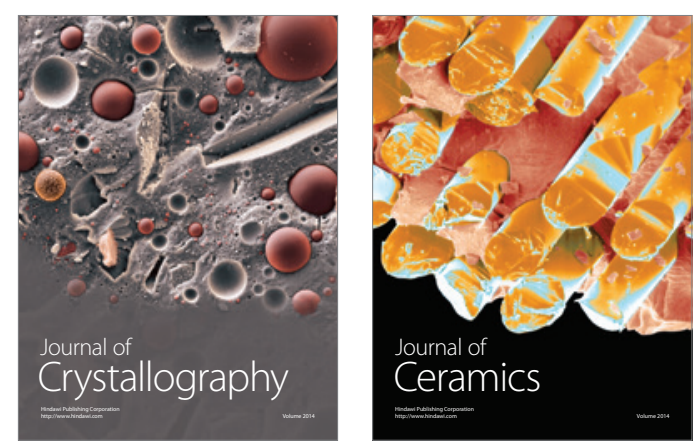
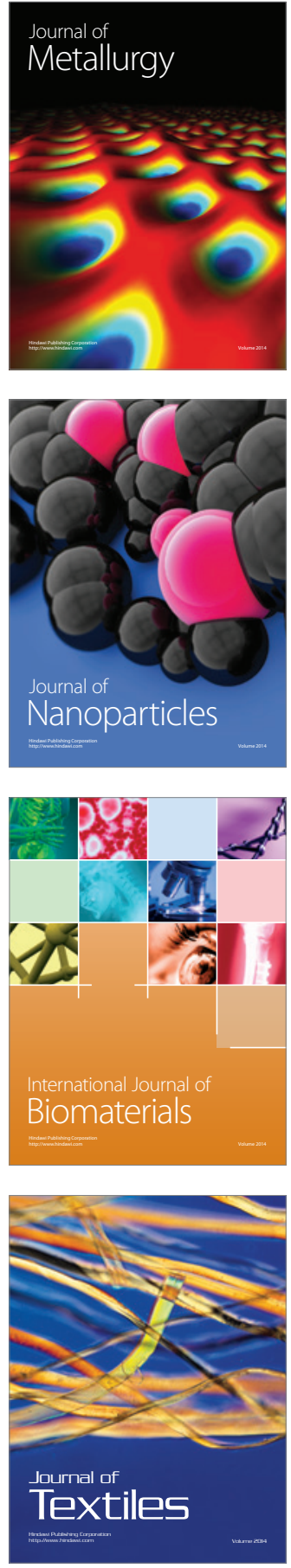